\title{
Recombinant Hepatocyte Growth Factor
}

National Cancer Institute

\section{Source}

National Cancer Institute. Recombinant Hepatocyte Growth Factor. NCI Thesaurus.

Code C1122.

A recombinant therapeutic agent which is chemically identical to or similar to the endogenous glycoprotein cytokine hepatocyte growth factor (HGF), which is produced by the liver and the pancreas. Endogenous HGF synthesis is stimulated by injuries affecting liver tissues. This agent, a potent angiogenic and neurotrophic factor and a multifunctional cytokine that acts as a mitogen, motogen and a morphogen, is important for organogenesis and tissue regeneration. Therapeutic HGF has been shown to attenuate brain ischemic injury in animal models through angiogenic and neuroprotective actions. ( $\mathrm{NCl04)}$ 